\title{
MEDIDAS PROVISÓRIAS, CONSTITUIÇÕES ESTADUAIS E FEDERAÇÃO
}

PROVISIONAL EXECUTIVE ORDERS, STATES CONSTITUTIONS, AND FEDERATION

\section{Álvaro Bettanin Carrasco*}

Sumário: Introdução. 1. O Estado Federal - Ordem Jurídica Total e Ordens Jurídicas Parciais. 2. A Posição do Supremo Tribunal Federal. 3. Análise dos Precedentes. Considerações Finais. Referências.

Resumo: $O$ presente trabalho trata de investigar a possibilidade de se prever, nas constituições dos estados da República Federativa do Brasil, autorização para que os respectivos governantes editem medidas provisórias. Aborda, ainda que de modo sucinto, as características de uma Federação, assim como analisa alguns precedentes do Supremo Tribunal Federal acerca da questão. Considerando-se o ordenamento jurídico brasileiro, e também o papel atual do Poder Executivo, não se encontra proibição à previsão, nas constituições dos estados federados, de medidas provisórias, conforme já decidiu, inclusive, a mais alta Corte do País. Entretanto, a necessidade de se observar o princípio da simetria parece enfraquecer a ideia de Federação, à semelhança do que já se verificou na ordem constitucional anterior.

Palavras-chave: Medidas Provisórias; Constituições dos Estados Federados; Poder Executivo; Federação; Princípio da Simetria.

\footnotetext{
* Universidade Federal do Rio Grande do Sul.
} 
Abstract: The present paper investigates the possibility of setting in the states constitutions of the Federative Republic of Brazil the authorization for respective governors to enact provisional executive orders. It approaches, even though briefly, the features of a Federation, as well as it analyses some precedents of the Brazilian Supreme Court on this matter. Considering Brazilian legal system and also the current role of Executive Branch, it is not found prohibition of setting, in the States Constitutions, Provisional Executive Order, in accordance with what has already decided the national highest Court. However, the need to comply with the federal symmetry principle seems to weaken the idea of Federation, similar to what has been verified in the previous constitutional order.

Keywords: Provisional Executive Orders; States Constitutions; Executive Branch; Federation; Federal Symmetry Principle.

\section{INTRODUÇÃO}

A par dos eventuais abusos denunciados pela doutrina acerca da utilização de medidas provisórias, ${ }^{1}$ é inegável que esses atos normativos com força de lei acabam desempenhando um importante papel no desenvolvimento de estratégias governamentais, sobretudo quando há dificuldades para uma atuação coordenada e articulada entre Governo e Parlamento. Com efeito, além de constituírem um instrumento disponível ao governante para questões de urgência e relevância, as quais não podem esperar o natural debate político intrínseco ao processo de elaboração das leis, as medidas provisórias também configuram, atualmente, uma alternativa às situações de impasse entre o Executivo e Legislativo.

É de se notar que as exigências do Estado Social tornam necessário o desenvolvimento de políticas públicas que reclamam uma aproximação entre o governante e o legislador, de modo que não há mais como se pensar numa separação de poderes (ou de funções estatais) enquanto simples mecanismo de "equilíbrio de forças políticas” (FERREIRA FILHO, 2009-b,

\footnotetext{
${ }^{1}$ Vejam-se, a propósito, as críticas realizadas por Manoel Gonçalves Ferreira Filho (2009-a, p. 237-41).
} 
p. 253). O Estado intervencionista realça a função governamental do Executivo, ${ }^{2}$ que passa a ser proeminente e decisivo na escolha do projeto político que irá ditar os rumos do País (não se limitando, portanto, à mera execução desse projeto), sem prejuízo do controle que deve ser exercido pelo Parlamento (FERREIRA FILHO, 2009-b, p. 262-8).

A descrição desse panorama, que evidentemente é passível de uma análise mais profunda, tem aqui o objetivo apenas de destacar a relevância do tema ora proposto. O que se pretende investigar nesse trabalho, na verdade, é a possibilidade de utilização de medidas provisórias pelos estados da Federação e a concepção de sistema federativo subjacente a essa questão.

Para tanto, será realizado um pequeno estudo acerca forma federativa de Estado, de extrema utilidade na busca de algumas possíveis respostas ao problema ora suscitado. Também é absolutamente pertinente observar-se a posição adotada pelo Supremo Tribunal Federal acerca da matéria, realizando-se, por fim, uma análise crítica dessa posição com base no referencial teórico adotado.

\section{O ESTADO FEDERAL - ORDEM JURÍDICA TOTAL E ORDENS JURÍDICAS PARCIAIS}

O estudo da forma de um Estado é, em linhas gerais, a verificação do modo como é repartido o poder no território desse Estado (SOUZA JUNIOR, 2002-b, p. 23). Dentre as diversas hipóteses de estruturação territorial, há aquela que aqui interessa: o Estado Federal.

Difícil é uma conceituação precisa de Estado Federal, tendo em vista as múltiplas formas de organização do espaço estatal assumidas ao longo da história, de acordo com as tradições, necessidades e peculiaridades dos povos (CARRAZZA, 2005, p. 124). Apesar disso, pode-se dizer que uma Federação caracteriza-se, essencialmente, por um Estado soberano composto de entes com certa autonomia política, constitucional, legislativa e

\footnotetext{
${ }^{2}$ Sobre a distinção entre as funções de chefia de Estado, chefia de Governo e Chefia da Administração, todas concentradas no Poder Executivo de acordo com a teoria clássica de tripartição dos poderes (que, por isso mesmo, é passível de ser superada), imprescindível é o estudo de Cezar Saldanha Souza Junior (2002-a).
} 
administrativa, advinda diretamente de uma Constituição, na qual se fundamenta a unidade indissolúvel desses entes e a identidade de seu povo. ${ }^{3}$

Numa perspectiva estritamente jurídica, um Estado Federal pressupõe a existência conjunta de diversos ordenamentos distintos: uma ordem total, que se refere a toda a Federação e limita autonomia das unidades federadas; uma ordem parcial central, que diz respeito às competências do poder centralizado; e várias ordens jurídicas parciais locais, as quais correspondem às competências distribuídas aos demais entes da Federação, e têm âmbito de vigência em frações do território nacional (KELSEN, 1934, p. 261-3).

No caso do ordenamento brasileiro, essa característica do Estado Federal pode ser claramente constatada. De fato, assim dispõe o artigo 18 da Constituição da República: “A organização político-administrativa da República Federativa do Brasil compreende a União, os Estados, o Distrito Federal e os Municípios, todos autônomos, nos termos desta Constituição".

Em outras palavras: a República Federativa do Brasil, isto é, a ordem total, compreende as ordens parciais da União, dos estados, do Distrito Federal e dos municípios. Os estados federados organizam-se por meio de suas constituições estaduais, enquanto o Distrito Federal e os municípios organizam-se por meio de leis orgânicas, sempre observadas as limitações estabelecidas pela Constituição da República.

No tocante à União, a sua organização vem regulada na própria Constituição de 1988 , de modo que no mesmo documento normativo é possível encontrar, além do conjunto de dispositivos aplicáveis ao Estado Federal, a ordem parcial específica do poder central (KELSEN, 1934, p. 273). ${ }^{4}$ É necessária, portanto, que se faça a distinção entre Constituição da República (ordem total) e Constituição Federal ou da União (ordem parcial), embora a determinação dos limites entre uma e outra certamente seja fonte de controvérsias e haja a utilização genérica da expressão "Constituição Federal".

Os dispositivos referentes à edição de medidas provisórias pelo Presidente da República, nesse contexto, parecem referir-se à Constituição da União, de maneira que tais normas constitucionais dizem respeito apenas à ordem jurídica central. Tal circunstância, por

\footnotetext{
${ }^{3}$ Nesse sentido, a compreensão de Carlos Eduardo Dieder Reverbel (2007, p. 53-4). Apesar da diversidade de entes federados, há uma nacionalidade federal (comum) dos indivíduos (KELSEN, 1979, p. 382).

${ }^{4}$ À mesma conclusão parece ter chegado Geraldo Ataliba (1980, p. 69), também com base na teoria de Kelsen.
} 
si só, não configura uma proibição constitucional à adoção de medidas provisórias pelos estados.

É preciso que se verifique, então, se a previsão de medidas provisórias nas constituições estaduais é incompatível com os princípios e regras da Constituição da República (ordem total). ${ }^{5}$ Oportuna, nesse momento, uma busca a precedentes do Supremo Tribunal Federal sobre o assunto, uma vez que aquela Corte é a intérprete final das normas constitucionais.

\section{A POSIÇÃO DO SUPREMO TRIBUNAL FEDERAL}

Três precedentes serão aqui considerados paradigmáticos para ilustrar o entendimento do Supremo Tribunal Federal acerca das medidas provisórias nas constituiçõos estaduais.

No primeiro deles, tratava-se de medida cautelar na ação direta de inconstitucionalidade n. 812, na qual se impugnavam os seguintes dispositivos da Constituição do Estado de Tocantins:

Art. 27

$[\ldots]$

$\S 3^{\circ}$. Em caso de relevância e urgência, o Governador do Estado poderá adotar medidas provisórias, com força de lei, devendo submetê-las de imediato à Assembléia Legislativa que, estando em recesso, será convocada extraordinariamente para se reunir no prazo de cinco dias.

$\S 4^{\circ}$. As medidas provisórias perderão eficácia, desde a edição, se não forem convertidas em lei no prazo de trinta dias, a partir de sua publicação, devendo a Assembléia Legislativa disciplinar as relações jurídicas delas decorrentes.

Debruçando-se sobre a questão de maneira superficial, pois se analisava pedido de liminar, o Supremo Tribunal Federal considerou não haver, em princípio, violação da

\footnotetext{
${ }^{5}$ José Afonso da Silva, aliás, já afirmou que há violação ao princípio da separação de poderes: "E medidas provisórias, podem as Constituições estaduais instituí-las? Em edições anteriores, respondemos que nada justificava sua existência no âmbito estadual, mas não víamos proibição em que o fizessem. Até onde sabemos, os Estados (e também os Municípios) evitaram adotá-las. E hoje, re melius perpensa, achamos ponderável o argumento de que, sendo exceção ao princípio da divisão de poderes, só vale nos limites estritos em que foram elas previstas na Constituição Federal, ou seja, apenas no âmbito federal, não se legitimando seu acolhimento nem nos Estados nem nos Municípios" (1996, p. 578) [destaques do autor].
} 
Constituição da República, tendo em vista a ausência de proibição expressa à previsão de medidas provisórias no âmbito estadual. $\mathrm{O}$ acórdão restou assim ementado:

Ação direta de inconstitucionalidade. PARS. 3. e 4. do artigo 27 da Constituição do Estado de Tocantins. Adoção de Medida Provisória no âmbito estadual. Pedido de liminar. - Não ocorrência, no caso, dos requisitos da concessão da cautelar. Pedido de liminar indeferido (BRASIL, STF, ADI 812 MC, Relator(a): Min. Moreira Alves, Tribunal Pleno, julgado em 01/04/1993, DJ 14-05-1993).

Essa ação direta acabou sendo julgada extinta sem resolução de mérito, sob o fundamento de que houve perda superveniente da legitimidade ativa do Partido Democrata Cristão, pois esse partido político deixou de ter representação parlamentar no Congresso Nacional.

De qualquer forma, as normas estaduais questionadas foram novamente objeto de análise pela Corte Constitucional, em sede de preliminar na ação direta de inconstitucionalidade n. 425. Nessa ação, o pedido não era exatamente o de julgar inconstitucional a previsão da edição de medidas provisórias pelo governo do Estado de Tocantins, eis que a demanda foi promovida para retirar do ordenamento determinadas leis estaduais resultantes da conversão daqueles atos normativos. Entretanto, dada a ligação dessa questão com a discussão acerca da competência para o governador valer-se de medidas provisórias, o Supremo Tribunal Federal acabou enfrentando o tema.

Como já sinalizado no precedente anteriormente citado, a Corte entendeu não haver restrição (vedação) constitucional quanto ao uso de medidas provisórias pelos estados federados, desde que adotadas as linhas básicas do modelo federal (aplicação do princípio da simetria quanto ao processo legislativo). De acordo com o voto do Ministro Relator, Maurício Correa, também nos estados pode haver a necessidade de o governador lançar mão do referido instrumento legislativo, à semelhança do que ocorre no âmbito da União, nada justificando a proibição cogitada.

Acrescentou o Ministro Celso de Mello que o artigo 25, § $2^{\circ}$, da Constituição da República, não permite entendimento em sentido diverso, porquanto esse dispositivo veda aos estados federados a regulamentação, por meio de medidas provisórias, da exploração dos 
serviços locais de gás canalizado. Estaria autorizada, portanto, a utilização de medidas provisórias para outras matérias.

A ementa da decisão é a seguinte:

\begin{abstract}
AÇÃO DIRETA DE INCONSTITUCIONALIDADE. PRELIMINAR. CONSTITUIÇÃO DO ESTADO. PROCESSO LEGISLATIVO. MEDIDA PROVISÓRIA. COMPETËNCIA DO GOVERNADOR PARA EDITÁ-LA. AUMENTO DE REMUNERAÇÃO DE SERVIDORES PÚBLICOS. INICIATIVA. DOAÇÃO DE BENS DO ESTADO. MAJORAÇÃO DO PERCENTUAL DE PARTICIPAÇÃO DOS MUNICÍPIOS NA ARRECADAÇÃO DO ICMS. EFICÁCIA LEGAL LIMITADA NO TEMPO. PREJUDICIALIDADE. 1. Podem os Estados-membros editar medidas provisórias em face do princípio da simetria, obedecidas as regras básicas do processo legislativo no âmbito da União (CF, artigo 62). 2. Constitui forma de restrição não prevista no vigente sistema constitucional pátrio $\left(\mathrm{CF}, \S 1^{\circ}\right.$ do artigo 25$)$ qualquer limitação imposta às unidades federadas para a edição de medidas provisórias. Legitimidade e facultatividade de sua adoção pelos Estados-membros, a exemplo da União Federal. [...] (BRASIL, STF, ADI 425, Relator(a): Min. Maurício Corrêa, Tribunal Pleno, julgado em 04/09/2002, DJ 1912-2003)
\end{abstract}

Essa posição restou consolidada no julgamento da ação direita de inconstitucionalidade n 2.391, em que se questionava a constitucionalidade dos seguintes dispositivos da Constituição de Santa Catarina:

Art. 51. Em caso de relevância e urgência, o Governador do Estado poderá adotar medidas provisórias, com força de lei, devendo submetê-las de imediato à Assembléia Legislativa, que, estando em recesso, será convocada extraordinariamente no prazo de cinco dias.

$\S 1^{\circ}$ As medidas provisórias perderão eficácia, desde a edição, se não forem convertidas em lei no prazo de trinta dias a partir de sua publicação, devendo a Assembléia Legislativa disciplinar as relações jurídicas delas decorrentes.

$\S 2^{\circ}$ É vedada a edição de medida provisória sobre matéria que não possa ser objeto de lei delegada.

$\S 3^{\circ}$ É vedada a reedição, na mesma sessão legislativa, de medida provisória não deliberada ou rejeitada pela Assembléia Legislativa. ${ }^{6}$

\footnotetext{
${ }^{6}$ Esse artigo foi alterado pela Emenda Constitucional n. 49, de 17 de julho de 2009, passando a ter a seguinte redação: "Art. 51. Em caso de relevância e urgência, o Governador do Estado poderá adotar medidas provisórias, com força de lei, devendo submetê-las de imediato à Assembléia Legislativa. $\S 1^{\circ}$ As medidas provisórias, ressalvado o disposto nos $\S \S 7^{\circ} \mathrm{e} 8^{\circ}$, perderão eficácia, desde a edição, se não forem convertidas em lei no prazo de sessenta dias, prorrogável, nos termos do $\S 6^{\circ}$, uma vez por igual período, devendo a Assembléia Legislativa
} 
Após o ajuizamento da demanda proposta, os dispositivos constitucionais que regulavam as medidas provisórias editadas pelo Presidente da República sofreram profundas modificações, em razão da Emenda Constitucional n. 32, de 11 de setembro de 2001.

O Supremo Tribunal Federal, partindo da premissa de que deveria existir uma simetria com os citados dispositivos constitucionais (disciplina dada à matéria no âmbito da União), entendeu estar prejudicada a ação direta no tocante às regras constitucionais estaduais de processamento das medidas provisórias que estivessem em desacordo com as novas regras estabelecidas para a União. Isso porque a mudança do parâmetro normativo teria acarretado a revogação dos dispositivos da Constituição Estadual.

Assim, remanesceu a discussão apenas acerca do caput do referido artigo 51, vale dizer, a discussão no Pretório Excelso acabou restringindo-se basicamente à possibilidade ou não de haver medidas provisórias no horizonte dos entes estaduais. O debate, aliás, foi bastante interessante, especialmente quanto ao conteúdo do princípio da separação de poderes e no que diz respeito ao papel atual do Executivo na organização estatal. ${ }^{7}$

Prevaleceu, por ampla maioria (vencido apenas o Ministro Carlos Ayres Britto), a tese de favorável à edição da Medida Provisória pelo governante estadual, sendo julgado improcedente o pedido formulado:

AÇÃO DIRETA DE INCONSTITUCIONALIDADE. ARTIGO 51 E PARÁGRAFOS DA CONSTITUIÇÃO DO ESTADO DE SANTA CATARINA. ADOÇÃO DE MEDIDA PROVISÓRIA POR ESTADO-MEMBRO. POSSIBILIDADE. ARTIGOS 62 E 84, XXVI DA CONSTITUIÇÃO FEDERAL.

disciplinar, por decreto legislativo, as relações jurídicas delas decorrentes. $\S 2^{\circ}$ É vedada a edição de medida provisória sobre matéria que não possa ser objeto de lei delegada. $§ 3^{\circ}$ É vedada a reedição, na mesma Sessão Legislativa, de medida provisória não deliberada ou rejeitada pela Assembleia Legislativa. $\S 4^{\circ} \mathrm{O}$ prazo a que se refere o $\S 1^{\circ}$ contar-se-á da publicação da medida provisória, suspendendo-se durante os períodos de recesso da Assembleia Legislativa. $\S 5^{\circ}$ Se a medida provisória não for apreciada em até quarenta e cinco dias, contados de sua publicação, entrará em regime de urgência, ficando sobrestadas, até que se ultime a votação, todas as demais deliberações legislativas da Assembleia Legislativa. $\S 6^{\circ}$ Prorrogar-se-á uma única vez por igual período a vigência de medida provisória que, no prazo de sessenta dias, contado de sua publicação, não tiver a sua votação encerrada na Assembleia Legislativa. § 7ํNão editado o decreto legislativo a que se refere o $\S 1$ o até sessenta dias após a rejeição ou perda de eficácia de medida provisória, as relações jurídicas constituídas e decorrentes de atos praticados durante a sua vigência conservar-se-ão por ela regidas.§ 8- Aprovado o projeto de lei de conversão alterando o texto original da medida provisória, esta manter-se-á integralmente em vigor até que seja sancionado ou vetado o projeto".

${ }^{7}$ A leitura do acórdão, também por isso, é altamente recomendável. 
EMENDA CONSTITUCIONAL 32, DE 11.09.01, QUE ALTEROU SUBSTANCIALMENTE A REDAÇÃO DO ART. 62. REVOGAÇÃO PARCIAL DO PRECEITO IMPUGNADO POR INCOMPATIBILIDADE COM O NOVO TEXTO CONSTITUCIONAL. SUBSISTÊNCIA DO NÚCLEO ESSENCIAL DO COMANDO EXAMINADO, PRESENTE EM SEU CAPUT. APLICABILIDADE, NOS ESTADOS-MEMBROS, DO PROCESSO LEGISLATIVO PREVISTO NA CONSTITUIÇÃO FEDERAL. INEXISTÊNCIA DE VEDAÇÃO EXPRESSA QUANTO ÀS MEDIDAS PROVISÓRIAS. NECESSIDADE DE PREVISÃO NO TEXTO DA CARTA ESTADUAL E DA ESTRITA OBSERVÂNCIA DOS PRINCÍPIOS E LIMITAÇÕES IMPOSTAS PELO MODELO FEDERAL. 1. Não obstante a permanência, após o superveniente advento da Emenda Constitucional 32/01, do comando que confere ao Chefe do Executivo Federal o poder de adotar medidas provisórias com força de lei, tornou-se impossível o cotejo de todo o referido dispositivo da Carta catarinense com o teor da nova redação do art. 62, parâmetro inafastável de aferição da inconstitucionalidade argüida. Ação direta prejudicada em parte. 2. No julgamento da ADI 425, rel. Min. Maurício Corrêa, DJ 19.12.03, o Plenário desta Corte já havia reconhecido, por ampla maioria, a constitucionalidade da instituição de medida provisória estadual, desde que, primeiro, esse instrumento esteja expressamente previsto na Constituição do Estado e, segundo, sejam observados os princípios e as limitações impostas pelo modelo adotado pela Constituição Federal, tendo em vista a necessidade da observância simétrica do processo legislativo federal. Outros precedentes: ADI 691, rel. Min. Sepúlveda Pertence, DJ 19.06.92 e ADI 812-MC, rel. Min. Moreira Alves, DJ 14.05 .93 . 3. Entendimento reforçado pela significativa indicação na Constituição Federal, quanto a essa possibilidade, no capítulo referente à organização e à regência dos Estados, da competência desses entes da Federação para "explorar diretamente, ou mediante concessão, os serviços locais de gás canalizado, na forma da lei, vedada a edição de medida provisória para a sua regulamentação" (art. $25, \S 2^{\circ}$ ). 4. Ação direta cujo pedido formulado se julga improcedente (BRASIL, STF, ADI 2391, Relator(a): Min. Ellen Gracie, Tribunal Pleno, julgado em 16/08/2006, DJ 16-032007).

Destaquem-se, por fim, as condições estabelecidas pelo Supremo Tribunal Federal para que o governador possa editar medidas provisórias: previsão expressa na Constituição Estadual e observância da simetria com o processo legislativo federal.

\section{ANÁLISE DOS PRECEDENTES}

De tudo o que se viu, pode-se inferir que o Supremo Tribunal privilegiou a Federação, garantindo, de certa forma, a autonomia dos entes estaduais. Além disso, é subjacente à posição do Pretório Excelso o reconhecimento de uma tendência a uma nova concepção do Poder Executivo, que passa a ser responsável pela condução da política nacional e pela satisfação das necessidades dos cidadãos, de modo que o Executivo, hoje, é Governo. ${ }^{8}$ Essa

8 Trata-se, segundo Manoel Gonçalves Ferreira Filho, de uma tendência do Direito Constitucional contemporâneo: "Se o Executivo hoje é Governo, isto resulta do fato de que é ele quem determina e conduz a política nacional. Zela pelo bem-estar do povo, regula a economia, assiste os cidadãos em muitas de duas 
nova concepção - exigência do Estado Social - é decisiva para que não se vislumbre, na adoção de medidas provisórias pelas constituições estaduais, violação à divisão de poderes.

Apesar disso, importa notar que a referida autonomia, segundo as decisões acima citadas, sofre um balizamento bastante considerável, decorrente da aplicação do princípio da simetria. Na verdade, tal princípio acaba funcionando, ao mesmo tempo, como fundamento e limitador da utilização de medidas provisórias na esfera estadual. ${ }^{9}$

Importa ressaltar que a matéria não é tida como de reprodução compulsória. As constituições estaduais não precisam necessariamente estabelecer a possibilidade de edição de medidas provisórias pelo chefe do Executivo. Entretanto, se isso ocorrer, deve ser observado o modelo da União (a cópia desse modelo é não uma mera faculdade, como ocorre com as chamadas "normas de imitação"). ${ }^{10}$

O entendimento de que é necessária a simetria com o processo legislativo federal talvez seja uma herança de dispositivos da Constituição de 1967. Com efeito, assim dispunha o seu artigo 13, III:

Art 13 - Os Estados se organizam e se regem pelas Constituições e pelas leis que adotarem, respeitados, dentre outros princípios estabelecidos nesta Constituição, os seguintes:

III - o processo legislativo;

necessidades, garante a ordem interna, a segurança internacional. Se ainda executa leis, o mais das vezes é quem as faz, legiferando por decretos-leis, medidas provisórias, leis delegadas, etc." (FERREIRA FILHO, 2009-b, p. 300-1).

${ }^{9}$ Roque Carrazza, a propósito, assim afirma: "Nada impede, porém, que, exercitando seus poderes constituintes decorrentes, os Estados, os Municípios e o Distrito Federal prevejam a edição de medidas provisórias, respectivamente, estaduais, municipais e distritais. A elas, mutatis mutandis, devem ser aplicados os princípios e limitações que cercam as medidas provisórias federais" (2005, p. 270-1, nota 35) [grifos do autor]. Alexandre de Moraes (2006, p. 617), por sua vez, sustenta que as alterações do modelo federal referentes às medidas provisórias, especialmente as decorrentes de Emenda Constitucional n. 32/01, não podem ser contrariadas pelas constituições estaduais.

${ }^{10}$ De acordo com Raul Machado Horta, “A norma de reprodução não é, para os fins da autonomia do EstadoMembro, simples norma de imitação, freqüentemente encontrada na elaboração constitucional. As normas de imitação exprimem a cópia de técnicas ou de institutos, por influência de sugestão exercida pelo modelo superior. As normas de reprodução decorrem do caráter compulsório da norma constitucional superior, enquanto a norma de imitação traduz a adesão voluntária do constituinte [estadual] a uma determinada disposição constitucional" (2002, p. 73). 
O artigo 188 daquela Carta, por sua vez, tinha a seguinte redação:

Art 188 - Os Estados reformarão suas Constituições dentro em sessenta dias, para adaptá-las, no que couber, às normas desta Constituição, as quais, findo esse prazo, considerar-se-ão incorporadas automaticamente às cartas estaduais.

Parágrafo único - As Constituições dos Estados poderão adotar o regime de leis delegadas, proibidos os decretos-leis.

Com o advento da Constituição de 1969 (Emenda Constitucional n. 1, de 17 de outubro de 1969), a situação não mudou. Ao contrário, além de ser mantida a norma do citado artigo 13, foi suprimido o prazo outrora estabelecido pelo artigo 188 acima transcrito:

Art. 200. As disposições constantes desta Constituição ficam incorporadas, no que couber, ao direito constitucional legislado dos Estados.

Parágrafo único. As Constituições dos Estados poderão adotar o regime de leis dêlegadas, proibidos os decretos-leis.

Como se pode observar, era efetivamente limitadíssima a autonomia dos estados federados, a ponto de José Afonso da Silva (1996, p. 101) referir que a Federação, naquela época, era apenas "nominal". ${ }^{11}$ De fato, quase nenhum espaço sobrava para a atividade do constituinte estadual, que se via obrigado a seguir uma padronização quase absoluta. Nesse contexto, era natural pensar-se na existência de uma simetria entre as "diversas" ordens jurídicas da Federação.

Esse quadro, entretanto, modificou-se substancialmente com a Carta de $1988 .{ }^{12}$ Não há dúvidas de que os dispositivos constitucionais atualmente vigentes, correspondentes aos da ordem constitucional anterior, são menos uniformizadores.

\footnotetext{
${ }^{11}$ Cezar Saldanha Souza Junior, tratando da Constituição de 1969, explica: “Alguns, no campo do governo, falaram da adoção de um novo modelo de federalismo, mais centralizado, o federalismo de integração. Outros, mais exaltados, no campo da oposição, chegaram a sustentar que a nova ordem abolira, pelo menos na prática, a Federação" (2002-b, p. 75) [grifos do autor].

12 Nesse sentido, a posição de Manoel Gonçalves Ferreira Filho: “As regras estabelecidas para o processo legislativo no plano federal já não são obrigatórias para os Estados federados. Não há na Constituição em vigor norma equivalente ao art. 200 da Emenda n. 1/69, o qual incorporava, no que coubesse, ao Direito Constitucional
} 
O artigo 25 da Constituição da República, a propósito, tem o seguinte teor: “Os Estados organizam-se e regem-se pelas Constituições e leis que adotarem, observados os princípios desta Constituição". No mesmo sentido, o artigo 11 do Ato das Disposições Constitucionais Provisórias: "Cada Assembléia Legislativa, com poderes constituintes, elaborará a Constituição do Estado, no prazo de um ano, contado da promulgação da Constituição Federal, obedecidos os princípios desta."

Da simples leitura e comparação entre os dispositivos transcritos é possível constatar que a autonomia dos entes estaduais é limitada, atualmente, apenas pelos princípios constitucionais, os quais, aliás, geralmente dizem respeito aos valores sobre os quais é construída a unidade nacional. ${ }^{13}$ Logo, tais princípios fazem parte da ordem total, a qual deve ser obedecida também pela ordem parcial da União. Não há mais a uniformização imposta pelo regime constitucional anterior, de modo que é questionável a aplicação do princípio da simetria com relação ao processo legislativo do poder central (FERREIRA FILHO, 2009-a, p. $254-5) .{ }^{14}$

O próprio Supremo Tribunal Constitucional, após a promulgação da Constituição da República, cogitou a hipótese de garantir maior autonomia aos entes estatais quanto ao processo legislativo. É o que se pode extrair do voto prolatado pelo Ministro Célio Borja, no julgamento da Medida Cautelar na Ação Direta de Inconstitucionalidade n. 216, do qual se transcreve o seguinte trecho:

Dir-se-á que na Constituição Federal vigente permanece entre os princípios sensíveis, de obrigatória observância pelos Estados, o sistema representativo (art. 34, VII, a , da Constituição Federal).

Ora, no conceito de sistema representativo não está incluído, necessariamente, o de processo legislativo, mormente com o alcance e o conteúdo que a Constituição

estadual as disposições constantes da Lei Magna Federal. Ora, por julgamento unânime da doutrina e da jurisprudência, um dos pontos em que essa incorporação cabia era exatamente o processo legislativo, ex vi do art. 13, III, da Emenda n. 1/69" (2009-a, p. 254).

13 Esses princípios, segundo Manuel Gonçalves Ferreira Filho, "são os enumerados no art. 34, VII [da Constituição da República], ou seja: ‘a) forma republicana, sistema representativo e regime democrático; b) direitos da pessoa humana; c) autonomia municipal; d) prestação de contas da administração pública, direta e indireta; e) aplicação do mínimo exigido da receita resultante de impostos estaduais, compreendida a proveniente de transferências, na manutenção e desenvolvimento do ensino e nas ações e serviços públicos de saúde (acrescentado pela EC n 29/00)"' (2009-c, p. 60).

${ }^{14}$ Roger Stiefelmann Leal (S.d) também aponta a forma centralizadora como tem sido interpretado o sistema federativo brasileiro, a despeito da maior autonomia estabelecida aos entes estaduais pela Constituição de 1988 . 
brasileira lhe dá - elaboração, redação, alteração e consolidação das leis (art. 59 e seu parágrafo único) [grifos do autor]. ${ }^{15}$

Entretanto, como já se deixou transparecer, acabou prevalecendo a tese mais centralizadora, mantendo-se o espírito da Constituição de 1969. Uma leitura das constituições estaduais ilustra essa situação, pois não é necessário muito esforço para perceber a grande similaridade existente entre elas, apesar das dimensões continentais do País e das notáveis peculiaridades de cada região. ${ }^{16}$

Especificamente no que concerne às medidas provisórias, a necessidade de os entes estaduais copiarem o modelo estabelecido para o Presidente da República parece não se coadunar com o sistema federativo. A propósito, se a Federação pressupõe a coexistência de ordens jurídicas parciais fundamentadas em uma ordem jurídica total, então não há

15 Eis a ementa do julgado: "AÇÃO DIRETA DE INCONSTITUCIONALIDADE - CONSTITUIÇÃO ESTADUAL - PROCESSO LEGISLATIVO - A QUESTÃO DA OBSERVÂNCIA COMPULSORIA, OU NÃO, DE SEUS PRINCÍPIOS, PELOS ESTADOS-MEMBROS - NOVA CONCEPÇÃO DE FEDERALISMO CONSAGRADA NA CONSTITUIÇÃO DE 1988 - PERFIL DA FEDERAÇÃO BRASILEIRA - EXTENSÃO DO PODER CONSTITUINTE DOS ESTADOS-MEMBROS - RELEVO JURÍDICO DO TEMA SUSPENSÃO LIMINAR DEFERIDA. O perfil da Federação brasileira, redefinido pela Constituição de 1988, embora aclamado por atribuir maior grau de autonomia dos Estados-membros, e visto com reserva por alguns doutrinadores, que consideram persistir no Brasil um federalismo ainda afetado por excessiva centralização espacial do poder em torno da União Federal. Se é certo que a nova Carta Política contempla um elenco menos abrangente de princípios constitucionais sensíveis, a denotar, com isso, a expansão de poderes jurídicos na esfera das coletividades autônomas locais, o mesmo não se pode afirmar quanto aos princípios federais extensíveis e aos princípios constitucionais estabelecidos, os quais, embora disseminados pelo texto constitucional, posto que não é tópica a sua localização, configuram acervo expressivo de limitações dessa autonomia local, cuja identificação - até mesmo pelos efeitos restritivos que deles decorrem - impõe-se realizar. A questão da necessária observância, ou não, pelos Estados-membros, das normas e princípios inerentes ao processo legislativo, provoca a discussão sobre o alcance do poder jurídico da União Federal de impor, ou não, às demais pessoas estatais que integram a estrutura da Federação, o respeito incondicional a padrões heterônomos por ela própria instituídos como fatores de compulsória aplicação. Esse tema, que se revela essencial a organização político-administrativa do Estado brasileiro, ainda não foi decidido pelo Supremo Tribunal Federal. Da resolução dessa questão central, emergira a definição do modelo de Federação a ser efetivamente observado nas práticas institucionais. Enquanto não sobrevier esse pronunciamento, impõe-se, como medida de cautela, a suspensão liminar de preceitos inscritos em Constituições estaduais, que não hajam observado os padrões jurídicos federais, de extração constitucional, concernentes ao processo legislativo". (BRASIL, STF, ADI 216 MC, Relator(a): Min. Célio Borja, Relator(a) p/ Acórdão: Min. Celso de Mello, Tribunal Pleno, julgado em 23/05/1990, DJ 0705-1993). O julgamento da referida ação foi tido como prejudicado, haja vista a perda superveniente do seu objeto.

${ }^{16}$ Apesar de Roque Carrazza parecer manifestar-se favoravelmente à regulação de medidas provisórias estaduais em conformidade com as medidas provisórias da União, ele sustenta que "cada Estado-membro, no Brasil, está autorizado a elaborar livremente sua Constituição, atendendo a suas características geográficas, sociais e históricas, bem como aos desejos e aptidões do povo que nele habita" (2005, p. 152-3). Acrescenta o autor, ainda, citando Ernesto Leme, que "não há por que as Constituições estaduais serem cópias servis da Constituição Federal. Basta que obedeçam aos preceitos capitulares que ela veicula (Federação, tripartição do poder, autonomia municipal etc). Por igual modo é de estranhar-se que, num país de dimensões continentais, como o nosso, as Constituições dos Estados sejam, se não idênticas, pelo menos vazadas nos mesmos moldes. Juridicamente, assim não precisaria ser (art. 25 da CF de 1988)" (2005, p. 153, nota 44). 
propriamente uma hierarquia entre a ordem jurídica parcial da União e as demais ordens jurídicas parciais.

Destarte, não se justifica a obrigatoriedade de as constituições estaduais observarem as regras e limitações impostas à edição de medidas provisórias pelo poder central. As unidades da Federação, na verdade, devem respeitar os princípios da Constituição da República (ordem total), e é com base nesses princípios que se pode manter a unidade nacional sem que ocorra necessariamente a abstração das diversas especificidades locais.

Dessas diferentes realidades brotam, aliás, as experiências indispensáveis para o conhecimento - sempre permanente - dos valores sobre os quais se estrutura toda a sociedade.

\section{CONSIDERAÇÕES FINAIS}

Não há vedação na Constituição da República para a previsão de medidas provisórias nas constituições estaduais. Nesse sentido já se manifestou o Supremo Tribunal Federal, acompanhando a circunstância de que uma tripartição de poderes, concebida simplesmente como uma separação e contrabalanço de forças, não cumpre as funções hoje esperadas do Estado.

Evidentemente, a utilização abusiva desses atos normativos não pode ser tolerada. As medidas provisórias são cabíveis em hipóteses específicas e com a observância de certos limites, de modo a evitar-se uma distorção desse importante instrumento de que dispõe o governante.

Também foi possível observar que não existe mais a imposição uniformizadora característica da ordem constitucional anterior, que praticamente retirava a autonomia do legislador constituinte estadual. Em que pese esse fato, a Corte Constitucional brasileira não abandonou a noção de simetria, exigindo-a no que se refere ao processo legislativo em geral e às medidas provisórias em particular.

Várias podem ser as razões pelas quais o Supremo Tribunal Federal tem adotado essa concepção centralizadora, e não cabe nesse momento investigá-las. Há quem entenda, inclusive, que é mais provável a acentuação do caráter centrípeto da Federação brasileira, 
tendo em vista que muito é esperado do poder central no sentido de promover o desenvolvimento, reduzir desigualdades etc. (FERREIRA FILHO, 2009-b, p. 295).

Embora essa realmente possa ser uma tendência (que inegavelmente mitiga a noção de ordens jurídicas parciais sem relação hierárquica entre elas), não é necessariamente a solução mais adequada para a harmonização das diversidades e manutenção da unidade do Estado brasileiro. Cezar Saldanha Souza Junior resume a questão: "Nossa realidade reclama por uma técnica por uma técnica centrífuga e por maior flexibilidade, orientada pelo princípio da subsidiariedade, que hoje está produzindo uma nova concepção de Federação em todo o mundo" (2002-b, p. 83).

\section{REFERÊNCIAS}

ATALIBA, Geraldo. Regime Constitucional e Leis Nacionais e Federais. Revista de Direito Público, São Paulo, n. 53-54, p. 58-76, jan.-jun., 1980.

CARRAZZA, Roque Antônio. Curso de direito constitucional tributário. $21^{\mathrm{a}}$ ed. São Paulo: Malheiros, 2005.

FERREIRA FILHO, Manoel Gonçalves. Do processo legislativo. $6^{\mathrm{a}}$ ed. São Paulo: Saraiva, 2009.

. Princípios fundamentais do direito constitucional. São Paulo: Saraiva, 2009.

. Curso de direito constitucional. 35ª ed. São Paulo: Saraiva, 2009.

HORTA, Raul Machado. Direito constitucional. $3^{\text {a }}$ ed. Belo Horizonte: Del Rey, 2002.

KELSEN, Hans. Teoría general del estado. Barcelona: Labor, 1934.

Teoría general del derecho y del estado. $2^{\mathrm{a}}$ ed. México: Universidade Nacional Autónoma de México, 1979. 
LEAL, Roger Stiefelmann. A autonomia do estado-membro e o papel do Supremo Tribunal Federal. Disponível em: < http://www.ppgd.ufrgs.br/doutrina/leal3.htm > Acesso em 12 de agosto de 2009.

MORAES, Alexandre de. Direito constitucional. 19ª ed. São Paulo: Atlas, 2006.

REVERBEL, Carlos Eduardo Dieder. Federalismo, descentralização e subsidiariedade. In: SOUZA JUNIOR, Cezar Saldanha; AVILA, Marta Marques (coord.). Direito do estado: estudos sobre federalismo. Porto Alegre: Dora Luzzatto, 2007.

SILVA, José Afonso da. Curso de direito constitucional positivo. $11^{\mathrm{a}}$ ed. São Paulo, Malheiros, 1996.

SOUZA JUNIOR, Cezar Saldanha. O tribunal constitucional como poder: uma nova teoria da divisão dos poderes. São Paulo: Memória Jurídica, 2002.

Constituições do Brasil. Porto Alegre: Sagra Luzzatto, 2002.

Submissão: 21/12/2013

Aceito para Publicação: 21/12/2013 